See discussions, stats, and author profiles for this publication at: https://www.researchgate.net/publication/262938837

Allen-Collinson, J and Leledaki, A (2015) Sensing the outdoors: a visual and haptic phenomenology of outdoor exercise embodiment, Leisure Studies 34

Article in Leisure Studies · May 2015

DOI: 10.1080/02614367.2014.923499

2 authors:

Jacquelyn Allen-Collinson

University of Lincoln

177 PUBLICATIONS $\mathbf{1 , 8 8 9}$ CITATIONS

8 PUBLICATIONS $\mathbf{7 5}$ CITATIONS

SEE PROFILE

SEE PROFILE

Some of the authors of this publication are also working on these related projects:

Project Local Healthy Food View project

Project Sociology of health and illness View project 
Authors' pre-publication copy - may contain typographical errors

To cite this article: Allen-Collinson, J. \& Leledaki, L. (2015) Sensing the outdoors: a visual and haptic phenomenology of outdoor exercise embodiment, Leisure Studies, 34 (4): 457-470.

DOI: $10.1080 / 02614367.2014 .923499$

To link to this article:

http://www.tandfonline.com/doi/pdf/10.1080/02614367.2014.923499

\section{Sensing the outdoors: a visual and haptic phenomenology of outdoor exercise embodiment}

Prof Jacquelyn Allen-Collinson, Director of Health Advancement

Research Team (HART), University of Lincoln, UK

E: jallencollinson@lincoln.ac.uk

Dr Aspasia Leledaki, Independent Researcher, Exeter, UK 


\section{Sensing the outdoors: a visual and haptic phenomenology of outdoor exercise embodiment}

In recent years, there has been a burgeoning of academic interest in exercise embodiment issues, including a developing field of phenomenologically-inspired analyses of the lived-body experience of physical activity and exercise. Calls have been made for researchers to explore the sensory dimension of such embodiment, and a corpus of sensory ethnographic studies is now beginning to grow, focusing on the ways in which people engage in 'making sense of the senses' within a socio-cultural framework. This article contributes to a developing body of phenomenological-sociological empirical work on the sensory dimension, by addressing the lived experience of organised physical activities in 'natural' outdoor leisure environments. We draw upon the findings from a two-year ethnographic study of a Welsh national physical activity programme, 'Mentro Allan/Venture Out', which aimed to increase physical activity levels amongst specific 'target groups'. Based on fieldwork and on interviews $(n=68)$ with Programme participants, here our analytic focus is upon the visual and the haptic dimensions of sensory engagement with organised outdoor leisure activities, including experiences of 'intense embodiment'.

Keywords: phenomenology; phenomenological sociology; intense embodiment; outdoor leisure; the senses; the haptic

\section{Introduction}

Over the last decade, there has been a burgeoning of academic interest in embodiment issues relating to leisure, physical culture and exercise, including a developing field of phenomenologically-inspired analyses of the lived experience of physical cultures and 
activities, for example, of women's sporting embodiment (Chisholm, 2008; AllenCollinson, 2009, 2011a, 2011b), running and scuba diving (Allen-Collinson \& Hockey, 2011), football (Hughson \& Inglis, 2002; Hemphill, 2005), distance walking (Crust, Keegan, Piggott \& Swann, 2011), parkour and freerunning (Clegg \& Butryn, 2012), yoga and meditation (Leledaki, 2014). The application of empirical forms of phenomenology to the detailed investigation of physical culture and exercise is perhaps not surprising, given phenomenology's potential in portraying vividly the 'here-and-now, raw reality of the body' (Sinclair, 2005, p. 90). A distinctive sub-field has also emerged in recent times, focusing upon sensory auto/ethnographic studies of various physical cultures and leisure activities (e.g., Sparkes, 2009; Allen-Collinson \& Hockey, 2011; Sparkes \& Smith, 2012).

This article contributes to a developing corpus of phenomenological-sociological empirical work on the sensory dimension, by addressing the lived experience of organised physical activity in outdoor leisure environments. It also contributes to the domain of sensory ethnography (Sparkes, 2009) in drawing upon the findings from a two-year ethnographic study ${ }^{1}$ of a Welsh physical activity programme, 'Mentro Allan' (Venture Out). Funded by the Big Lottery Fund (BLF) as part of the UK-wide Community Sport Initiative (CSI), and rolled out in fifteen different projects across Wales (both urban and rural), this Programme aimed to increase physical activity levels amongst specific 'target groups' considered to be less physically active than the population in general (BLF, 2009). One of the key aims of the programme was to utilise the outdoor environment of Wales, where a decision was made to focus on encouraging physical activity generally rather than specific involvement in 'sports'. The programme

\footnotetext{
${ }^{1}$ The overall research project utilised a mixed-methods approach, but here it is the ethnographic component upon which we focus.
} 
funded 14 different projects across Wales, providing support to a range of target groups such as young single mothers, people with physical disabilities, those with learning difficulties, people with mental health issues, the over 50s, 'disengaged' young people, and those from Black Minority and Ethnic (BME) communities. As Woodward (2009, p. 145) notes, material bodies embody inequalities and are both represented and experienced as 'marginalised'. Drawing upon de Beauvoir's (1989, p. 66) insights, she highlights how bodies position themselves and are also positioned by others, so that the body can be portrayed as a situation. Our bodies can thus be marginally situated via a gamut of structural and cultural forces, on the grounds of, for example, age, gender, 'race', ethnicity, dis/ability and so on. Locating bodies as 'marginalised' and 'less active' was central to the Mentro Allan Programme, which incorporated two key aims: i) to motivate a diverse range of less active groups to engage (and sustain engagement) with physical activity; and ii) to focus on physical activity in the 'natural' environment.

The 'natural' is of course a highly problematic term within the social sciences, and indeed was critically discussed as part of the research project. The working definition that came to be adopted was based on Clayton and Opotow's (2003, p. 6) description: 'environments in which the influence of humans is minimal or non-obvious, to living components of that environment (such as trees...), and to non-animate natural environmental features'. Definitions of the 'natural environment' differed widely between participants and contexts, however, and we wished to remain open to participants' own definitions of what was, for them, deemed natural. The Mentro Allan Programme itself aimed to engage people in outdoor leisure and physical activity by using 'doorstep' locations, in order to minimise the impact of travel and to maximise accessibility and sustainability. The focus in the current article is not on evaluating the success (or otherwise) of the Programme in promoting behaviour change (see for 
example, Hutchison, Johnston, \& Breckon, 2013, for a discussion). Rather, we subject to analysis participants' sensory experiences in the outdoor environment as part of their engagement with the Programme, because the sensory emerged as salient in their lived experiences. Nevertheless, the importance of sensory engagement with the outdoors may well have implications for policy-makers, as positive, pleasurable sensory experiences may well help motivate sustained exercise participation in outdoor environments (AllenCollinson, Curry, Leledaki \& Clark, 2011).

The article is structured as follows. We first provide a brief overview of phenomenological sociology and how phenomenologically-inspired perspectives have in recent years been utilised within studies of physical activity and leisure. We then turn to consider the developing field of the sociology of the senses, drawing upon sensory ethnographic and autoethnographic studies of exercise and physical activities. A brief portrayal of the two-year ethnographic project from which the data are drawn then follows, before addressing the principal sensory findings, which cohere around two key themes: the visual and the haptic dimensions of physical activity in outdoor leisure environments. These were the elements of the sensorium ${ }^{2}$ that emerged most strongly in participant accounts.

\section{Phenomenological-sociological perspectives}

\footnotetext{
${ }^{2}$ defined here as the human perceptual apparatus in toto, as experienced in everyday
} life 
Despite early forays into phenomenology vis-à-vis exercise and movement (e.g. Arnold, 1979), a phenomenologically-orientated corpus on exercise and physical cultures has been relatively slow to emerge. In more recent years, research in the sociology and philosophy of sport has begun to address the specific potential of phenomenologicallyinspired theories and approaches for the investigation of physical activities (see for example, Kerry \& Armour, 2000; Hockey \& Allen-Collinson, 2007; Allen-Collinson, 2009, 2011a, 2011b; Hogeveen, 2011; Martínková \& Parry, 2011; Ravn \& Hansen, 2013). All these authors furnish detailed accounts of sport- and physical culture-related phenomenology, so here we provide just a brief résumé for those unfamiliar with this approach.

Developed by the German philosopher, Husserl, modern-day phenomenology is the study of something that is manifest to consciousness. Intentionality was a key element in Husserl's (1970) thinking, referring to the notion that human consciousness is always directed toward someone or something, including an idea. The relationship between individual human consciousness and the world is at the heart of phenomenology. Phenomenological researchers adopt the 'phenomenological attitude', involving epoche or bracketing (see Allen-Collinson, 2011a, for a detailed discussion). Thus the phenomenologist seeks temporarily to take a step back from the world of everyday, taken-for-granted understandings (our 'natural attitude'), 'in order to contemplate what it is to be a participant in the world, and how things present themselves to us' (Sokolowski 2000, p. 48). In brief, the aim is to approach the phenomenon under study with an open and questioning attitude, a sense of child-like wonder, suspending as far as possible our taken-for-granted, everyday assumptions.

Whilst Husserl's focus was primarily on the mind-world nexus, existential phenomenologists such as Merleau-Ponty (2001) have highlighted the corporeal element 
of existence, positing the importance of the 'lived body' (Leib), a body that links mindbody-world in an indissoluble relationship, our 'being-in-the-world' (Dasein). Given the importance accorded to the body in Merleau-Pontian thought, his existential phenomenological perspective has proved germane to the investigation of a range of physical cultures and leisure activities, such as football (Hughson and Inglis, 2002), parkour and freerunning (Clegg \& Butryn, 2012), distance running (Allen-Collinson, 2011b; Hockey 2012), fell-running (Nettleton, 2013), scuba diving (Allen-Collinson \& Hockey, 2011), and dance (Ravn \& Hansen, 2013). Research drawing upon other phenomenological traditions has also explored leisure experience, for example in relation to a Heideggerian-inspired analysis of skydiving (Breivik, 2010). In this article, we draw upon what has been conceptualised as phenomenologically-inspired sociology (AllenCollinson, 2011b), a phenomenological form that also acknowledges the myriad effects of culture, of the historical 'moment' and of social-structural elements upon lived-body experience.

Applying Merleau-Pontian phenomenological insights and of direct relevance to our interest in embodiment issues, Leder's (1990) concept of the 'disappearing' and 'dysappearing' body is germane to our analysis. Leder (1990) describes how the healthy body is usually in our everyday life largely 'absent' from our conscious awareness, it disappears; it is not the object of our intentionality, which is directed elsewhere to engaging with the world. In contrast to the state of disappearance, the body can be brought to heightened awareness when pain, illness or intense sensation, remind us of corporeal presence and disrupt the body-world relationship. Then the body dys-appears, and is brought - sometimes acutely - to consciousness (Leder 1990) becoming the object of our intentionality. We revisit this notion of dys-appearance below in the section on 'Elemental haptics', in portraying what we term 'intense embodiment' experiences, 
which similarly involve a high level of conscious awareness of the body as an object of intentionality but without the more negative connotations of 'dys' (signifying 'bad'/'abnormal').

Having furnished a brief resumé of our phenomenologically-inspired approach, we now turn to discuss the sociology of the senses in order to contextualise the sensory data that emerged so strongly from the research project.

\section{Sensuousities}

A body of literature in the sociology of the senses has begun to develop in recent years ${ }^{3}$, drawing upon sensory scholarship in cognate disciplines such as anthropology (e.g. Howes, 1991; Classen, 1993) and geography (Paterson, 2007). Indeed, there has occurred something of a 'sensorial revolution', as Howes (2006) indicates. This developing oeuvre also draws our analytic attention to the socio-historical and cultural specificities of sensory experience (e.g. Howes, 1991; Classen, 1993; Allen-Collinson \& Hockey, 2011; Vannini, Waskul \& Gottschalk, 2011; Low, 2012). The importance of the senses in social life is neatly encapsulated by Bull, Gilroy, Howes and Kahn (2006, p. 5), who highlight how: 'The senses mediate the relationship between self and society, mind and body, idea and object'. The active 'production' of the sensory is also emphasized, for social actors must undertake work in sensory-production as well as in sensoryinterpretation (Chau, 2008). Furthermore, the synaesthetic aspect - vis-à-vis the senses working in concert - should be emphasized.

\footnotetext{
${ }^{3}$ By this, we mean a substantial and coherent body of literature. There is of course a long history of more sporadic studies of the senses within sociology, for example, Simmel's (1908) essay on the Sociology of the Senses.
} 
Calls have recently been made (e.g. Mason \& Davies, 2009; Pink, 2009; Sparkes, 2009) for qualitative research into the complexities of lived sensory experience. Based on the ethnographic element of the Mentro Allan/Venture Out research, described below, this article responds to that call by contributing to a developing sociological literature on the senses. Within leisure and exercise-related studies, a developing body of research, including (auto)ethnographic work, is now beginning to explore the sensuous dimension, for example, Sparkes' (2009) evocative autoethnographic vignettes of cricketing, footballing and gym experiences, Wacquant's (2004) and Spencer's (2013) sensuouslygrounded ethnographic studies of boxing and mixed martial arts respectively, Humberstone's (2011) portrayal of windsurfing, Hockey \& Allen-Collinson's (2007) research on the sensory dimension of the sporting body generally, and specific studies of distance running and scuba diving (Allen-Collinson \& Hockey, 2011), and Merchant's (2011) vivid videographic study of scuba diving.

The Mentro Allan research revealed the importance of the sensorial elements of participants' engagement with exercise in outdoor leisure environments. Here, we focus specifically upon the visual and haptic dimensions, as these were the elements that emerged most frequently in interviewees' accounts during data analysis. In lived experience, however, these vectors of sensory perception are usually intertwined with other elements of the sensorium, to provide a synaesthetic experience (Allen-Collinson, 2011a) where the senses intermingle. Prior to portraying our sensory data, we provide a brief description of the mixed-methods project from which our findings are drawn; a highly detailed portrayal is included in the full research report (Allen-Collinson et al., 2011).

\section{The Mentro Allan research project}


The overarching aim of the funded research was to evaluate the Welsh national physical activity Programme, Mentro Allan, by investigating whether and in what ways, this was successful in increasing and sustaining increased physical activity levels amongst target groups of relatively inactive people in Wales. Ethical approval for the project was granted by the relevant University Ethics Committee. A mixed-methods approach was adopted, combining survey data with in-depth qualitative methods, including an ethnographic study of six specific projects, involving participant observation with a range of activity groups over a period of almost two years. It is this qualitative and phenomenologicallyinspired component of the research upon which we focus in this article. The purpose of this research was to investigate participants' lived-body experiences of engaging in the wide range of outdoor exercise opportunities provided by the 14 projects. In addition to participant observation, in-depth interviews - primarily semi-structured but also including some unstructured conversational interviews - were undertaken with 68 exercise participants, called 'beneficiaries' in the terminology of the Programme. These participants were selected via purposive sampling (and also some opportunistic sampling for the unstructured conversational interviews, which took place during activities) across all the projects, via criteria of gender, age, degree of dis/ability, type of activity, in order to provide a wide range of perspectives. Representativeness and generalisability were not, however, aims of the qualitative research, either from the perspective of the client or the researchers. Interviews were also conducted with project staff and other people involved in the Programme, such as volunteer workers and support workers, as follows:

Project staff:

(service providers, volunteers \& support workers): 
The key aim of the qualitative component of the project was to allow participants to portray their own lived experiences and to identify what was significant to them in engaging with exercise. Phenomenological bracketing or epochē was undertaken (see also Allen-Collinson, 2009, 2011a) throughout the research, in an attempt to suspend, as far as possible, our preconceptions regarding engaging in exercise in the outdoor environment. This was particularly important in relation to assumptions often made regarding the appropriateness of certain forms of exercise for particular social groups, for example, 'older' people, and BME participants, particularly women observing religious principles such as wearing the hijab. ${ }^{4}$ Future papers from the research will address the experiences of specific groups.

Most 'formal' interviews were around an hour's duration, whilst the 'informal' conversational interviews undertaken during activities were of shorter duration. For us, as for many phenomenologically-inspired researchers, the interviews were relatively unstructured, open and conversational, giving interviewer and interviewees the freedom to express and explore ideas, rather being constrained by a strict schedule. This approach constructs the interviewee as co-researcher (Brinkman \& Kvale, 2005), regarding her/him as the expert in the lived experience of the phenomenon/phenomena under study. Along with other qualitative researchers, we also adhere to the notion that interviews do not provide transparent windows to some inner private self (Smith \& Sparkes, 2005) but are co-constructions, interactionally produced. The interviews were transcribed by a

\footnotetext{
${ }^{4}$ From the Arabic: to veil, seclude; generally in Britain used as the term for the traditional head, face or body covering of women, originating in the Middle East and the Islamic world.
} 
specialist audio-transcriber. Both data collection and data analysis were phenomenologically-inspired, followed Giorgi's (1997) phenomenological guidelines (see also Allen-Collinson, 2011a), in that they involved: i) the collection of concrete descriptions of phenomena from a participant perspective; ii) the adoption of the phenomenological attitude via bracketing; iii) initial impressionistic readings of the transcripts to gain a feel for the whole; iv) followed by in-depth re-reading of descriptions as part of the data-immersion process, to identify key themes and sub-themes; v) the production of general statements of the patterns of participant experiences.

\section{The findings}

Whilst our participants were not asked specifically about the sensory elements of their experiences, nevertheless sensory engagement with the outdoor leisure activities appeared to resonate deeply with many, particularly in relation to the visual and haptic dimensions.

\section{The visual wonders of the natural world}

For participants, exercising in the outdoor environments of Wales generated a sense of wonderment, and 'nature connection' (White, 2013), particularly for those who were more accustomed to living in an urban, industrial environment. The overwhelming majority of 'wonderment' comments related to the visual dimension; it was the sights of nature that provoked feelings of wonder and delight:

Well actually, there was one occasion we were out on a Nordic walk... and we seen an orchid, a wild orchid, and we just all stopped and we were all looking and then we were looking for others, and it's quite amazing, it's quite child-like really, and it was just so wonderful and you see things and you think, look at that, look at the leaves on that, and 'oh look at that,' a dragonfly or some beetle or something, and 
as I say it's quite child-like you get that wonder... (older female participant)

This walk to the seaside ... I love nature and water, as a child I was born and lived in East Africa on the Indian Ocean, only 10-min walk from the Indian ocean, beautiful water and water has always had some fascination to me (female BME participant)

Different views, mountains, rivers, waterfalls, nature, different trails all the time. Everything's different when you come, nothing is the same every week (male participant with mental health problems)

Cherished memories of 'nature connection' (White, 2013) as a child were reported as being evoked by, for example, seeing the sea again as an adult. Sobel (1996) argues that during childhood, there is a strong connection with nature that can be nurtured through ecophilia - a loving and caring attitude towards nature, which some of the Mentro Allan projects also sought to instil or rekindle in their participants. For some, the experience of wonderment related particularly to seeing animals they had never encountered in the wild before, or to learning to 'see' the differences between those animals:

Learning, seeing. I have seen so much stuff that I have never seen in my 38 years basically. And it's amazing what I've seen. I've never seen an adder before. I'd never seen a grass snake before. I'd never seen a lizard. I've seen frogs and toads but wouldn't have been able to distinguish the two. I can now (female participant and volunteer helper) 
For many participants, the visual pleasures of the outdoor environments emerged as salient, with the sights of the 'natural world' being contrasted favourably with the vistas of 'man-made', 'modern' environments, particularly by those resident in more urban areas:

I prefer the natural world to the man-made world. I find the modern man- made world is very eye sore-ish. It looks like very tatty and run down and it's not very inspiring, but nature can beat anything that men make. That's why I prefer the natural world (older female participant).

I like being up high [when going climbing], I like seeing the world. I want to see it [world] as the nature intended it, not as people in the world muck it up... I want to see it as it really is ... (young male participant, under-18)

I appreciate the colours on the tree, the flowers, different wild flowers have different colours, I love the violet blue, it is all nature, nothing man made (older female participant).

Well it's where we're all one isn't it? Regardless of the fact that we've got all this technology and all the rest of it, but we're still part of nature aren't we? (older female participant, 65+).

Relative definitions of the natural in relation to visual perception also emerged as salient. For some urban-dwellers, their local urban green space was found to offer visual engagement with 'nature' (c.f. Barton, Hine \& Pretty, 2009). In most urban and suburban settings, however, as Alexander (2013) notes, many 'natural' areas such as parks, canals, and gardens, are actually artificial, being planned, landscaped and physically constructed by humans. As Gieryn (2000, p. 465) notes, as human actors we put as much effort into 
constructing the 'supposedly pristine places of Nature' as we do into cities or buildings. So, for many of our participants, local urban and suburban parks and green spaces were viewed and construed as natural places. They valorised the visual experiences offered by these places, which they felt preserved at least some elements of the 'countryside' within the city, and they were often prepared to travel intra-city to a specific urban park or green space they found particularly appealing. Primarily, it was the visual pleasures of looking at nature, including flora and fauna, that emerged as key elements, albeit often intertwined with other senses such as the auditory. In the following instances, two urbanbased BME female participants signalled the visual pleasures and 'refreshment' of visits to urban parks:

I live in $\mathrm{X}$ but here is water and big trees ... much nicer houses ... I am looking! ... Everything is nature, enjoy the nature.

I go to the park, I see squirrels running, I see birds talking to each other, they 'coo' each other, so it's nice to see them. It freshens your brain, it gets your cobwebs out.

In contrast to the urban projects based in industrial South Wales cities, other Mentro Allan projects covered a more rural catchment area, and participants reported feeling that the degree of human 'interference' decreased the further away from habitation or visibly 'managed land' they were. In effect, the more unspoilt and untouched the environment was perceived to be, the more natural, 'countryside' and 'refreshing' an experience it was deemed to offer, cohering with English early twentieth-century notions of the countryside as providing 'refreshment' (Joad, 1937, p. 82). For other more urbanbased projects, however, a large park in an urban location was often perceived by participants as extending into 'wild land' or 'countryside', blurring for them the 
urban/rural distinction. Definitions of 'natural' and 'outdoor' were therefore found to be complex and context-dependent, with shifting visions coming into play. An urban park might be seen as 'outdoor' and 'natural' by one person, but barely count as 'outdoor', let alone 'natural', for another. Whatever the differences in terms of envisioning and interpreting the natural, when other forms of sensory engagement were recounted, particularly relating to the haptic, it seemed to be the pleasures - and sometimes the displeasures - of encountering the elements in the outdoor environment that were emphasized. We thus now proceed to examine participant accounts of being-in-theelemental-world, and to address the felt phenomenology (Allen-Collinson \& Hockey, 2011) of outdoor leisure spaces.

\section{Elemental haptics}

Paterson (2007) argues for a plurality of senses of touch to accommodate the complexity of this sense, highlighting phenomenological attention to touch and proprioception, perceived as integral to a 'felt phenomenology'. Proprioception relates to the perception of one's body in space, and also our 'inward' perception, for example, of deep muscles and tissues (Potter 2008). This wider, more encompassing notion of touch has been termed by some writers 'the haptic', and we address below the touch/haptic nexus.

Whilst deriving from the Greek haptesthai meaning 'pertaining to touch', the kind of touch implied by the term 'haptic' usually extends well beyond cutaneous contact, to include internally-felt sensations, which Paterson (2009) terms the 'somatic senses'. The haptic, for Paterson (2009), therefore incorporates kinaesthesia (a sense of movement), proprioception (one's felt-body position in space) and the vestibular system (sense of balance). We too are in agreement with the inclusion of these wider elements, but would further extend the concept of proprioception to include other components. 
'Proprioception' often relates to a kind of inward-feeling, sense of oneself (the 'proprio' element), usually taken to focus on neuromuscular perception and the position of one's body or limbs in space, but our wider usage of the term also incorporates notions of the 'visceral', defined as 'the realm of internally-felt sensations' (Hayes-Conroy \& HayesConroy, 2008, p. 462).

This more encompassing definition of the haptic seemed to reflect more accurately our participants' accounts of being in the outdoor environments and encountering the 'touch' of the elements. The difficulties of verbally and textually representing sensory experience have been discussed in the literature (Allen-Collinson \& Owton, 2012; Sparkes \& Smith 2012) and are acutely brought home to us in re-reading, out of context, some of the quotes that follow below. There are considerable challenges in portraying in analytic textual discourse the kinds of bodily practices and experiences not usually expressed verbally or visually, the 'unrepresentable' (Merchant, 2011), or at least the 'difficult to represent'. We found this to be the case in relation to the more visceral and proprioceptive elements of participants' experiences, particularly those of 'intense embodiment' and heightened sensory awareness. As many phenomenologists acknowledge, some experiences are pre-reflective - beyond language (Allen-Collinson, 2009) - and there are thus limitations to the translation and interpretation of sensory 'data', much of which are more figurative and evocative than literal. Our participants (and we ourselves) thus often found it difficult to describe haptic experiences. Perhaps the accounts below will evoke in the reader's body a vicarious multi-sensorial response; a form of sensory intersubjectivity (Allen-Collinson \& Owton, 2012) if these accounts reverberate with her/his lived experience, despite the limitations of textual representation. 
Elemental encounters certainly appeared to generate intense embodied experiences, with some participants valorising and celebrating being-in-the-elemental world, even when rainy, 'awful' or 'rubbish' weather conditions prevailed. Heightened sensory awareness and the exhilaration of being up on top of moors and mountains in high winds were described with relish by one participant:

... do you know what, I really like it when the weather's really rubbish as well; sometimes it's just crazy, in the winter going up where it's really snowy or when the weather's really awful and the wind's howling across and you're just basically having to hold on to rocks and not get blown off the top of the hill, it's brilliant, you just laugh and it's great. I just love it up there (young female participant)

Even the often maligned British rain evoked pleasure in some, as another noted:

Love it, I love the rain. I'm not afraid of the rain. If I'm going for a walk, I go for a daily walk, and if it's raining I'll still go, it won't prevent me from leaving my house or anything like that. It's just rain. Most people don't want to get wet, and they've got an umbrella and they stay in and stuff like that, or get a blanket and put a DVD on - it's just another day to me, it's just raining. The weather doesn't put me off at all (young male participant)

For many participants, however, there was evidence of having to engage in 'sensory work' (Vannini et al., 2011) and sensory learning, in order to become comfortable with, and appreciate elemental haptics. Those unfamiliar with outdoor leisure and exercise sometimes struggled to cope with the elements, particularly with the 'touch' of rain, which could generate intense negative embodiment experiences. A 
support worker noted how she had to persevere with some of her younger clients, including one who initially wouldn't go out at all in rainy conditions:

Just perseverance, because when he first came to us last year, he wouldn't go out in the rain, even a drop, even a drizzle, we'd have major crises with him, but now, that's what I'm saying about, for him, he's experienced all this that he wouldn't normally experience. We're not making them do it, but because we're there and it rains, well it's raining, we're going to get wet... if you want to stay on the bikes you can get wet, if you want to stay dry you'll have to get off the bike, so it's his choice to stay on (female support worker).

In some cases, such sensory elemental learning was more directed and formalised. Project staff and support workers recounted deliberate efforts at exposing their protégé(e)s to a range of weather conditions in order to enhance sensory development, so that the touch of rain or cold became part of their somatic learning, including for those with learning disabilities:

We've decided that we'd just go regardless of the weather. We'd maybe shorten the visit but we'll still go, because again you need that sensory input, as long as they're warm enough, they won't be getting hypothermia, and they need to experience cold, they need to experience wet, because that's part of their sensory development... The only thing we wouldn't do is if it's snowing but we go out all weathers, it doesn't matter what the weather (female support worker of young people with learning disabilities)

Included within the Mentro Allan Programme were some environmental 
educational initiatives that encouraged participants to learn about nature through discovery, observation and reflection in the outdoor environments. Whilst the visual sense undoubtedly played an important role, for example, in the identification of, and acquisition of knowledge about flora and fauna, other elements of the sensorium such as the olfactory and the haptic were also signalled as important by both beneficiaries and project staff. Some project leaders, for example, sought to instil a heightened degree of awareness of and attentiveness to the natural environment via multiple sensory modes, for example taking beneficiaries for walks through sensory gardens designed to stimulate olfactory and haptic senses as well as the visual. As Ingold (2001) notes in relation to the multi-sensory processes of learning: to 'show' something to someone is to cause it to be made present for that person, so that s/he can apprehend it directly, whether by looking, listening or feeling.

In the above data sections, we have focused upon the visual and haptic dimensions of sensory engagement with outdoor environments. In the concluding section, we link these findings to the wider literature on the senses and on the phenomenology of embodiment.

\section{Conclusion}

This article seeks to contribute to the developing field of sensory ethnography (Pink, 2008; Sparkes, 2009) and also to a small body of sociological phenomenological empirical work on the sensory dimension, by addressing the lived experience of organised leisure and physical activity in outdoor environments. Utilising insights derived from a sociologised form of phenomenology, in this article we have examined just some of the sensory experiences of participants in the Mentro Allan programme, focusing upon the visual and the haptic. That is not to say that other sensory experiences were not evident in our data, they most certainly were; but for our participants, the most 
often reported senses - often recounted in vibrant detail - were those of sight and touch vis-à-vis the outdoor environments. Delving further into the haptic data, it emerged that it was the touch of the elements (wind and rain primarily) that participants encountered as a vivid and key structure of experience in relation to exercising outdoors. Both the visual and the haptic contributed, it seemed, to experiences of what we term 'intense embodiment' (Allen-Collinson \& Owton, 2014): periods of heightened awareness of corporeal existence.

Intense embodiment experiences have, we argue, commonalities with Leder's (1990) phenomenologically-inspired concept of the dys-appearing body, described above. Intense embodiment similarly involves a high level of conscious awareness of the body as an object of intentionality but without necessarily incorporating the more negative connotations of $d y s-$ (signifying 'bad'/'abnormal') appearance. Intense embodiment connotes a positively heightened sense of corporeal 'aliveness', of the senses working at an intense level, the kind of bodily 'high' so vividly described by Shilling and Bunsell (2009) in relation to the workout experiences of female bodybuilders, where pleasure and pain boundaries blur, and muscles work 'to the max' (2009, p. 153). For many of our Mentro Allan participants, exercising in the outdoors also seemed to generate this sense of the 'dys-appearing' body, when they experienced the haptic discomforts of cold and rain. Such corporeal awareness was not always displeasurable, however, and elemental encounters were also described as generating some of the most pleasurable instances of 'intense embodiment' and elemental 'highs'. Indeed, for many participants it was 'being-in-the-outdoor-world' that was recounted as one of the key motivations for sustaining engagement with the Mentro Allan Programme; indoor exercise simply did not hold the same attractions, unless the weather was particularly inclement. 
Commensurate with the spirit of phenomenology, we have made best efforts to describe participants' lived experiences without reverting to over-theorisation and abstraction, but instead seeking to remain true to the grounded, somatic detail of their accounts, their narrated corpo-reality. As sociologists, however, we have also sought to situate these bodily, phenomenal accounts in a wider theoretical and conceptual context, drawing upon recent work in the sociology of the senses. The synthesis of phenomenology and sociology creates a challenging and, at times, an uneasy nexus (see also Allen-Collinson, 2011b). Our contribution to sociological phenomenology is, we hope, in accordance with phenomenology's own relatively modest claims vis-à-vis providing detailed, grounded, descriptions of concrete phenomena as lived in quotidian lives by everyday life-world participants, whilst avoiding grand theorisations.

In response to the 'so what?' question, we would argue that, whilst acknowledging fully the importance of analysing leisure experiences and participation at the macro, structural, ideological and discursive levels, some analytic balance is also desirable. Undue analytic emphasis on the abstract, macro and discursive can sometimes result in the neglect of the particular, existential, material dimension, and the undertheorisation of the lived, and often intensely corporeal aspects of our leisure activities, including the sensuous dimension. The epistemological importance of the sensory has been highlighted, for example, by Stoller (1989, p. 37) who asks, 'How can we know if we cannot see, touch or smell the phenomenon?'. Furthermore, sociological phenomenology provides us with a potent means of situating individuals' lived bodily experience within wider social structures. Our chosen 'sociologised' form of phenomenology thus emphasizes the ways in which embodied experience is lived within and through social structure, and is historically-specific, thus addressing the oft-cited 
critique of 'traditional' phenomenology as being uncritically universalist, and neglectful of the vast power of social-structural forces.

\section{Acknowledgements}

The research upon which this article is based was commissioned and funded by Sport Wales to evaluate the Mentro Allan Programme. Mentro Allan was a Big Lottery-funded initiative managed by a National Partnership of organisations: Sport Wales, Countryside Council for Wales, Public Health Wales, Wales Council for Voluntary Action, and the Welsh Local Government Association. The final project report can be found on ResearchGate at:

https://www.researchgate.net/publication/262938837_AllenCollinson_J_and_Leledaki_A_2015_Sensing the outdoors_a_visual_and haptic phen omenology_of_outdoor_exercise_embodiment_Leisure_Studies_34_4_457-470 


\section{References}

Alexander, V.D. (2013). Views of the neighbourhood: a photo-elicitation study of the built environment. Sociological Research Online, 18(1), 10. Available at:

http://www.socresonline.org.uk/18/1/10.html

Allen-Collinson, J. (2009). Sporting embodiment: sports studies and the (continuing) promise of phenomenology. Qualitative Research in Sport and Exercise, 1(3), 279296.

Allen-Collinson, J. (2011a). Intention and epochē in tension: autophenomenography, bracketing and a novel approach to researching sporting embodiment. Qualitative Research in Sport, Exercise and Health, 3(1), 48-62.

Allen-Collinson, J. (2011b). Feminist phenomenology and the woman in the running body. Sport, Ethics and Philosophy, 5(3), 287-302.

Allen-Collinson, J., Curry, N., Leledaki, A., Clark, M. (2011). Mentro Allan/Venture Out Evaluation: Lived Experiences of Physical Activity in Outdoor Environments. Final Report to Sport Wales. Cardiff: Sport Wales/Chwaraeon Cymru, 301 pp.

Allen-Collinson, J. \& Owton, H. (2012). Take a deep breath: asthma, sporting embodiment, the senses, and 'auditory work'. International Review for the Sociology of Sport. Online early at:

http://irs.sagepub.com/content/early/2012/11/04/1012690212463918

Allen-Collinson, J. \& Owton, H. (2014 in press). Intense embodiment: Senses of heat in women's running and boxing. Body \& Society.

Allen-Collinson, J. \& Hockey, J. (2011). Feeling the way: notes toward a haptic phenomenology of scuba diving and distance running. International Review for the Sociology of Sport, 46(3), 330-345. 
Arnold, P.J. (1979). Meaning in movement, sport and physical education. London: Heinemann.

Barton, J., Hine, R., \& Pretty J. (2009). The health benefits of walking in greenspaces of high natural and heritage value. Journal of Integrative Environmental Sciences, 6(4), $1-18$.

Big Lottery Fund (BLF) (2009). Summary of the Community Sport Initiative: Year three evaluation report. London: BLF. Available from: www.biglotteryfund.org.uk

Breivik, G. (2010). Being-in-the-void: a Heideggerian analysis of skydiving. Journal of the Philosophy of Sport, 37, 29-46.

Brinkman, S., \& Kvale, S. (2005). Confronting the ethics of qualitative research. Journal of Constructivist Psychology, 18, 157-181.

Bull, M., Gilroy, P., Howes, D., \& Kahn, D. (2006). Introducing sensory studies. The Senses and Society, 1(1), 5- 8.

Chau, A.Y. (2008). The sensorial production of the social. Ethnos, 73(4), 485-504.

Chisholm, D. (2008). Climbing like a girl: an exemplary adventure in feminist phenomenology. Hypatia, 23(1), 9-40.

Classen, C. (1993). Worlds of sense: Exploring the senses in history and across cultures. London: Routledge.

Clayton, S.D., \& Opotow, S. (2003). Identity and the natural environment: the psychological significance of nature. Cambridge, MA: MIT Press.

Clegg, J. L., \& Butryn, T. (2012). An existential phenomenological examination of parkour and freerunning. Qualitative Research into Sport, Exercise and Health, 4(3), 320-340. 
Crust, L., Keegan, R., Piggott, D., \& Swann, C. (2011). Walking the walk: a phenomenological study of long distance walking. Journal of Applied Sport Psychology, 23(3), 243-262.

de Beauvoir, S. (1989 [1949]). The second sex (trans. Parshey, H.M.). New York: Random House.

Gieryn, T.F. (2000). A space for place in sociology. Annual review of sociology, 26, 463-496.

Giorgi, A. (1997). The theory, practice, and evaluation of the phenomenological method as a qualitative research procedure. Journal of Phenomenological Psychology, 28, 235-261.

Hayes-Conroy, A., \& Hayes-Conroy, J. (2008). Taking back taste: Feminism, food and visceral politics. Gender, Place and Culture, 15, 461-473.

Hemphill, D. (2005). Deeper inside the beautiful game. Journal of the Philosophy of Sport, XXXII, 105-115.

Hockey, J., \& Allen-Collinson, J. (2007). Grasping the phenomenology of sporting bodies. International Review for the Sociology of Sport, 42 (2), 115-131.

Hogeveen, B. (2011). Skilled coping and sport: promises of phenomenology. Sport, Ethics and Philosophy, 5(3), 245-255.

Howes, D. (Ed.) (1991). The varieties of sensory experience: a sourcebook in the anthropology of the senses. Toronto: University of Toronto Press.

Howes, D. (2006). Charting the sensorial revolution. Senses and Society, 1(1), 113-128.

Hughson, J., \& Inglis, D. (2002). Inside the beautiful game: towards a Merleau-Pontian phenomenology of soccer play. Journal of the Philosophy of Sport, XXIX, 1-15.

Humberstone, B. (2011). Embodiment and social and environmental action in naturebased sport: spiritual spaces. Leisure Studies, 30, 495-512. 
Husserl, E. (1970). The crisis of European sciences and transcendental phenomenology, trans. Carr, D. Evanston, IL: Northwestern University Press.

Hutchison, A.J., Johnston, L.H., \& Breckon, J.D. (2013). A grounded theory of successful long-term physical activity behaviour change. Qualitative Research in Sport, Exercise and Health, 5(1), 109-126.

Ingold, T. (2001). From the transmission of representations to the education of attention. In H. Whitehouse (Ed.), The debated mind: evolutionary psychology versus ethnography (pp. 113-153). Oxford: Berg.

Joad, C.E.M. (1937). The people's claim. In C.W. Ellis (Ed.), Britain and the Beast (pp.64-85). London: J.M. Dent \& Sons.

Kerry, D.S., \& Armour, K.M. (2000). Sports sciences and the promise of phenomenology: Philosophy, method, and insight. Quest, 52(1), 1-17.

Leder, D. (1990). The absent body. Chicago: University of Chicago.

Leledaki, A. (2014). Body-selves and health-related narratives in modern yoga and meditation methods. Qualitative Research in Sport, Exercise \& Health, 6(2): 278300.

Low, K.S. (2012. The social life of the senses: charting directions. Sociology Compass, 6(3), 271-282.

Martínková, I., \& Parry, J. (2011). An introduction to the phenomenological study of sport. Sport, Ethics and Philosophy, 5(3), 185-201.

Mason, J., \& Davies, K. (2009). Coming to our senses? A critical approach to sensory methodology. Qualitative Research, 9(5), 587-603.

Merchant, S. (2011). The body and the senses: visual methods, videography and the submarine sensorium. Body and society, 17, 53-72. 
Merleau-Ponty, M. (2001. Phenomenology of perception, trans. C. Smith. London: Routledge \& Kegan Paul.

Nettleton, S. (2013). Cementing relations within a sporting field: Fell running in the English Lake District and the acquisition of existential capital. Cultural Sociology, 7(2), 196-210.

Paterson, M. (2007). The senses of touch: Haptics, affects and technologies. Oxford: Berg.

Paterson, M. (2009). Haptic geographies: ethnography, haptic knowledges and sensuous dispositions. Progress in Human Geography, 33(6), 766-788.

Pink, S. (2009). Doing sensory ethnography. London: Sage.

Potter, C. (2008). Sense of motion, senses of self: becoming a dancer. Ethnos, 73(4), 444465.

Ravn, S., \& Hansen, H.P. (2013). How to explore dancers' sense experiences? A study of how multi-sited fieldwork and phenomenology can be combined. Qualitative Research in Sport, Exercise and Health, 5(2), 196-213.

Shilling, C., \& Bunsell, T. (2009). The female bodybuilder as a gender outlaw. Qualitative Research in Sport and Exercise, 1(2), 141-159.

Sinclair, A. (2005). Body and management pedagogy. Gender, Work and Organization, 12(1), 89-104.

Smith, B. \& Sparkes, A. (2005). Analyzing talk in qualitative inquiry: exploring possibilities, problems and tensions. Quest, 57, 213-242.

Sobel, D. (1996). Beyond ecophobia. Great Barrington, MA: Orion Society.

Sokolowski, R. (2000). Introduction to phenomenology. Cambridge: Cambridge University Press. 
Sparkes, A. (2009). Ethnography and the senses: challenges and possibilities. Qualitative Research in Sport and Exercise, 1(1), 21-35.

Sparkes, A., \& Smith, B. (2012). Embodied research methodologies and the senses in sport and physical culture: A fleshing out of problems and possibilities. In K. Young \& M. Atkinson (Eds), Qualitative Research in Sport and Physical Culture (pp.169192). Castle Hill, Au: Emerald Press.

Spencer, D.C. (2013). Sensing violence: An ethnography of Mixed Martial Arts. Ethnography. Online early version available at:

http://eth.sagepub.com/content/early/2013/01/31/1466138112471108

Stoller, P. (1989). The taste of ethnographic things: The senses in anthropology. Philadelphia: University of Pennsylvania Press.

Vannini, P., Waskul, D., \& Gottschalk, S. (2011). The senses in self, society, and culture: a sociology of the senses. New York: Routledge.

Wacquant, L. (2004). Body and soul: Notebooks of an apprentice boxer. Oxford: Oxford University Press.

White, P.R. (2013). An autophenomenographical investigation of nature connection: A transpersonal focus. Ecopsychology, 5(4): 242-254.

Woodward, K. (2009). Bodies on the margins: Regulating bodies, regulatory bodies, Leisure Studies, 28(2), 143-156 